\title{
APLIKASI MONITORING DENYUT JANTUNG BERBASIS ANDROID
}

\author{
Muh Fahmi Rustan \\ Prodi Informatika, Fakultas Teknik, Universitas Sulawesi Barat \\ muhfahmi@unsulbar.ac.id
}

\begin{abstract}
ABSTRAK
Denyut jantung dapat memberi informasi bermanfaat dalam hal kesehatan, berubahnya pola denyut jantung dapat menandakan masalah medis yang berdampak pada tingkat kebugaran manusia. Penelitian ini bertujuan merancang aplikasi monitoring denyut jantung pada tubuh manusia yang didesain secara mobile sehingga dapat dengan mudah dalam melakukan pengukuran dimana saja, teknologi yang digunakan tergolong Low Power dan mobile serta sangat memungkinkan masyarakat yang berada pada daerah terpencil dapat memperoleh layanan kesehatan yang lebih baik. Metode yang digunakan berbasis eksperimental yaitu perancangan, pembuatan prototype dan pengujian. Hasil penelitian bahwa gelombang denyut jantung yang diperoleh menggunakan pulse sensor dibuat semirip mungkin sehingga dapat diterapkan pada sebuah sistem informasi kesehatan yang terhubung dengan koneksi internet yang memungkinkan tersedianya sebuah sistem yang dapat menghubungkan dokter dan pasien yang dapat membantu proses analisis kondisi kesehatan pasien tanpa mengharuskan pasien bertemu langsung dengan tim medis. Kesimpulan dari penelitian ini adalah hasil pembacaan memiliki tingkat error yang kecil sebesar $1.63 \%$. Selain itu sistem yang ada pada tim medis maupun admin dapat monitoring data denyut jantung pasien secara realtime, pasien juga dapat melihat medical record kapan saja dan dimana saja.

Kata Kunci : pulse sensor,kesehatan, medical record, Internet.
\end{abstract}

\section{ABSTRACT}

Perceiving the heart beat can give the useful information concerning health, the heart beat pattern change can signify the medical matter, which give impact on the human fitness level. The research aimed to conduct the monitoring system of the real time heart beat designed simply, so that it can carry out the measurement easily, cheaply because it uses Low Power and mobile, and it enables the community which is in the remote area to obtain the better health service. The research used the experimental bases methods namely: the designing, prototype making, and testing. The research result indicates that the heart beat wave obtained using the pulse sensor is made as closely as possible, so that it can be applied in the health information system connected to the internet which is enables the availability of a system which can connect the doctors and patients being able to help the analysis process of the patients' health conditions without compelling the patients to meet the medical team directly. The conclusion of the research is that the reading result has the small error rate of $1.64 \%$. Besides, the existing system in the medical and administrative teams can monitor the real time patients' heart beat data, the patients can also perceive their medical records anytime and anywhere.

Keywords: Health, pulse sensors, medical records, Internet. 


\section{PENDAHULUAN}

Sebuah Teknologi pada bidang medis diperlukan untuk meningkatkan pelayanan kesehatan terhadap pasien dikarenakan peningkatan mobilitas masyarakat saat ini. Hal yang mendasar adalah kesehatan jantung, indikator terpenting dalam menentukan kesehatan manusia adalah suhu tubuh, denyut jantung dan pernafasan. Mengetahui denyut jantung dapat memberi informasi kesehatan. Menurut AHA (American Heart Association, 2016), berapa kali jantung berdetak per menit dapat mengisyaratkan tingkat kebugaran pada manusia. Survei Sample Regristration System (SRS) pada 2014 di Indonesia menunjukkan, Penyakit Jantung Koroner (PJK) menjadi penyebab kematian tertinggi pada semua umur setelah stroke, yakni sebesar 12,9\%. Kemenkes imbau masyarakat agar melakukan cek kesehatan secara berkala, enyahkan asap rokok, rajin beraktifitas fisik, diet yang sehat dan seimbang, Bagi kebanyakan orang dewasa denyut jantung normal jumlahnya antara 60 dan 100 denyut per menit (Liu et al., 2012). Denyut nadi merupakan hasil representasi dari denyut jantung, posisi terbaik untuk mendapatkan denyut nadi berada pada bagian diantaranya pergelangan tangan, dalam siku, sisi leher, dan diatas kaki, untuk mendapatkan data yang paling akurat dapat menempatkan jari di atas denyut nadi dan menghitung jumlah denyut dalam 60 detik. Cara tersebut tergolong konvensional dan tidak efisien, pengukuran dengan cara lain dapat menggunakan teknik elektronik yakni menggunakan EKG (Elektrokardiogram) namun perangkat tersebut tergolong perangkat yang mahal dan harus di damping tim medis dalam menggunaakannya, dibutuhkan cara cepat, akurat dan sifatnya mobile untuk alasan praktis dalam mendapatkan hasil denyut nadi dan dapat dipantau oleh tim medis secara berkala dengan data yang realtime.

Tahap awal yang dilakukan pada penelitian ini adalah dengan perangkat mobile pengukur denyut jantung dengan menggunakan mikrokontroler Arduino UNO (Arduino, 2018) yang dilengkapi dengan perangkat bluetooth dan sensor pulse (Pulse Sensor, 2018) data denyut jantung diperoleh dari perangkat mikrokontroller yang sudah dilengkapi sensor dan modul yang terintegrasi dengan perangkat smartphone android melalui koneksi bluetooth. Hasil perhitungan denyut jantung direkam dan disimpan pada web server yang menjadi pusat penyimpanan data medis pasien. Tentunya tim medis yang berada pada lokasi yang berbeda dapat melakukan pemantauan secara realtime sehingga data dapat 


\section{Journal Of Computer and Information System (J-CIS)}

ISSN 2622-0881 (online)

diperoleh dan diolah secara langsung untuk melakukan diagnosa guna tindakan medis selanjutnya.

Tujuan dari pada penelitian ini adalah merancang sistem monitoring denyut jantung realtime yang didesain secara sederhana, Low Energy dan mobile serta sangat memungkinkan masyarakat yang berada pada daerah terpencil dapat memperoleh layanan kesehatan yang lebih baik.

\section{PENELITIAN TERKAIT}

Beberapa penelitian terkait menggunakan Photoplethysmograph telah dilakukan oleh Nuary (2010) dan Sonal et al (2014), dengan menyimpan data pulse yang disimpan pada aplikasi kesehatan yang dirancang. Penelitian lainnya yaitu pengembangan tampilan visual data medis pada jaringan telemedis interaktif (Santi dkk., 2013), sistem yang dikembangkan adalah telemedis interaktif dengan mengambil data dari perangkat sensor mikrokontroller yang terintegrasi dengan perangkat komputer dan terhubung dengan web server menggunakan kabel LAN.

\section{BAHAN DAN METODE}

\section{Lokasi dan Rancangan Penelitian}

Lokasi pengambilan data dapat dilakukan dimanapun selama tercoverage sinyal internet, juga dapat dilakukan pada daerah terpencil yang sulit di akses karena sifatnya mobile dan tim medis dapat memantau hasil pengukuran secara realtime. Jenis penelitian yang dilakukan merupakan penelitian percobaan yang dilakukan secara sistematis sesuai dengan metode waterfall (Pressman, 2009), yang menghasilkan perangkat prototype yang secara garis besar penelitian ini meliputi analisa kebutuhan dilanjutkan dengan perancangan perangkat lunak (Software) dan perangkat keras (Hardware) hasil akhir dengan melakukan pengukuran yang tampil pada perangkat output aplikasi.

\section{Sumber Data}

Data yang digunakan pada penelitian ini adalah vital sign (tanda vital) yaitu denyut nadi dengan rentang usia remaja hingga dewasa untuk dijadikan sebagai bahan sampel data untuk diproses dan divalidasi keakuratannya, data masukan berupa data denyut nadi yang merupakan representasi dari denyut jantung, atau berupa jumlah jantung berdetak 
per menit (Asfuah, 2012), sehingga hasil yang diperoleh bisa dijadikan acuan untuk pemanfaatan pengembangan kedepannya.

\section{Metode Analisis data}

Data masukan diperoleh menggunakan perangkat sensor yang terhubung dengan smartphone dianalisis secara kuantatif dengan menggunakan Relative Error Measurement dalam mengukur tingkat kesalahan data masukan yang diperoleh dari perangkat sensor yang dibandingkan dengan hasil pengukuran secara manual. Data tersebut diambil dan disimpan langsung secara realtime pada server pusat dapat dilihat ilustrasi alur pengiriman data pada Gambar 1.

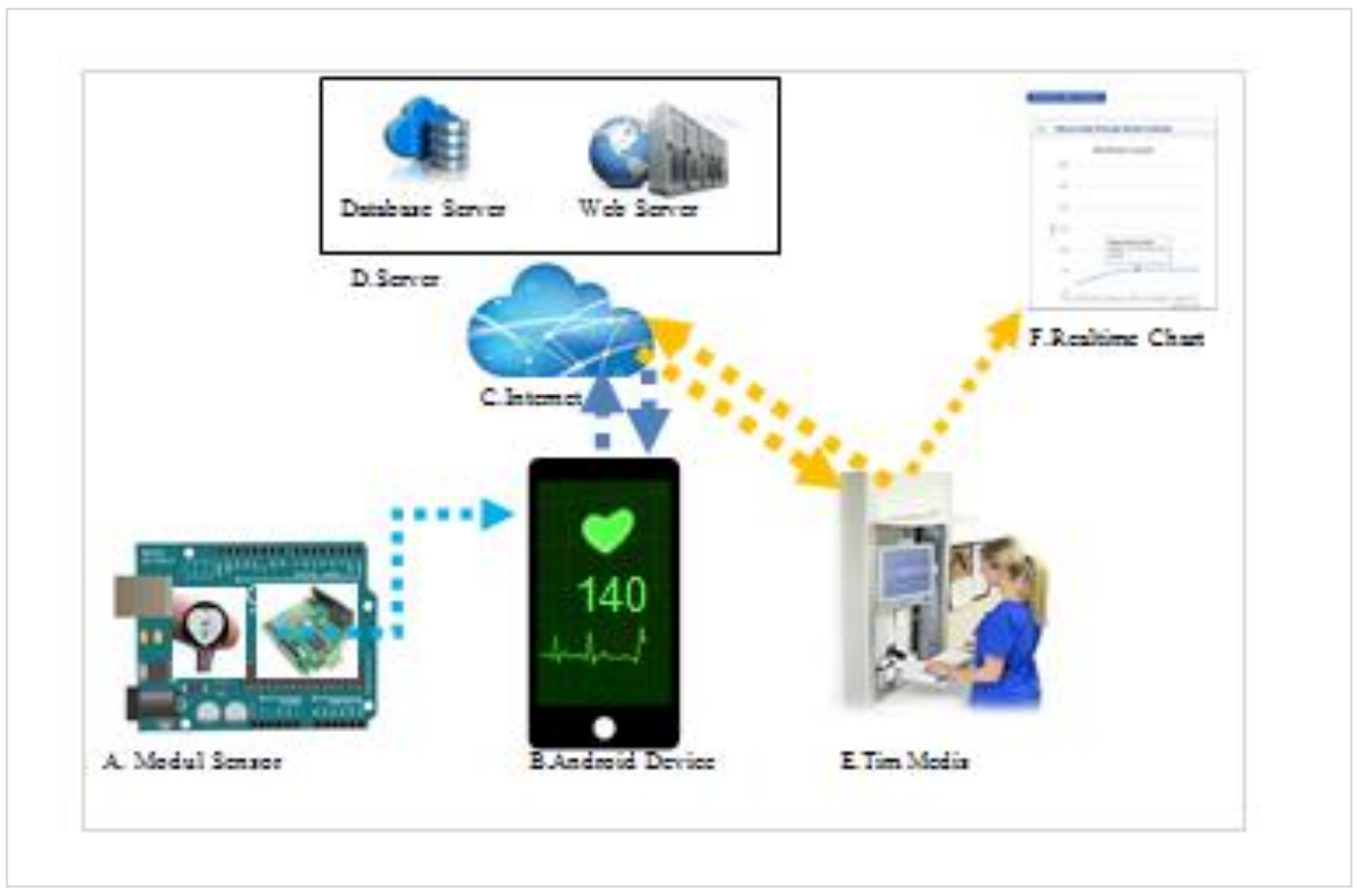

\section{Gambar 1. Diagram rancangan sistem}

\section{HASIL PENELITIAN}

\section{Pengujian Sensor}

Pertama dilakukan pengujian fungsionalitas dengan memastikan pulse sensor bekerja dengan baik sehingga pada saat proses penghitungan dapat menghasilkan grafik gelombang yang dapat dibaca oleh sistem dimana gelombang tersebut terdapat titik Peak 
(P) dan Trough( $\mathrm{T}$ ) (Pulse Sensor, 2016), sistem ini secara otomatis menggunakan algoritma penentuan titik puncak (peak detection) dimana proses penghitungan detak jantung permenit terlihat pada Gambar 2.
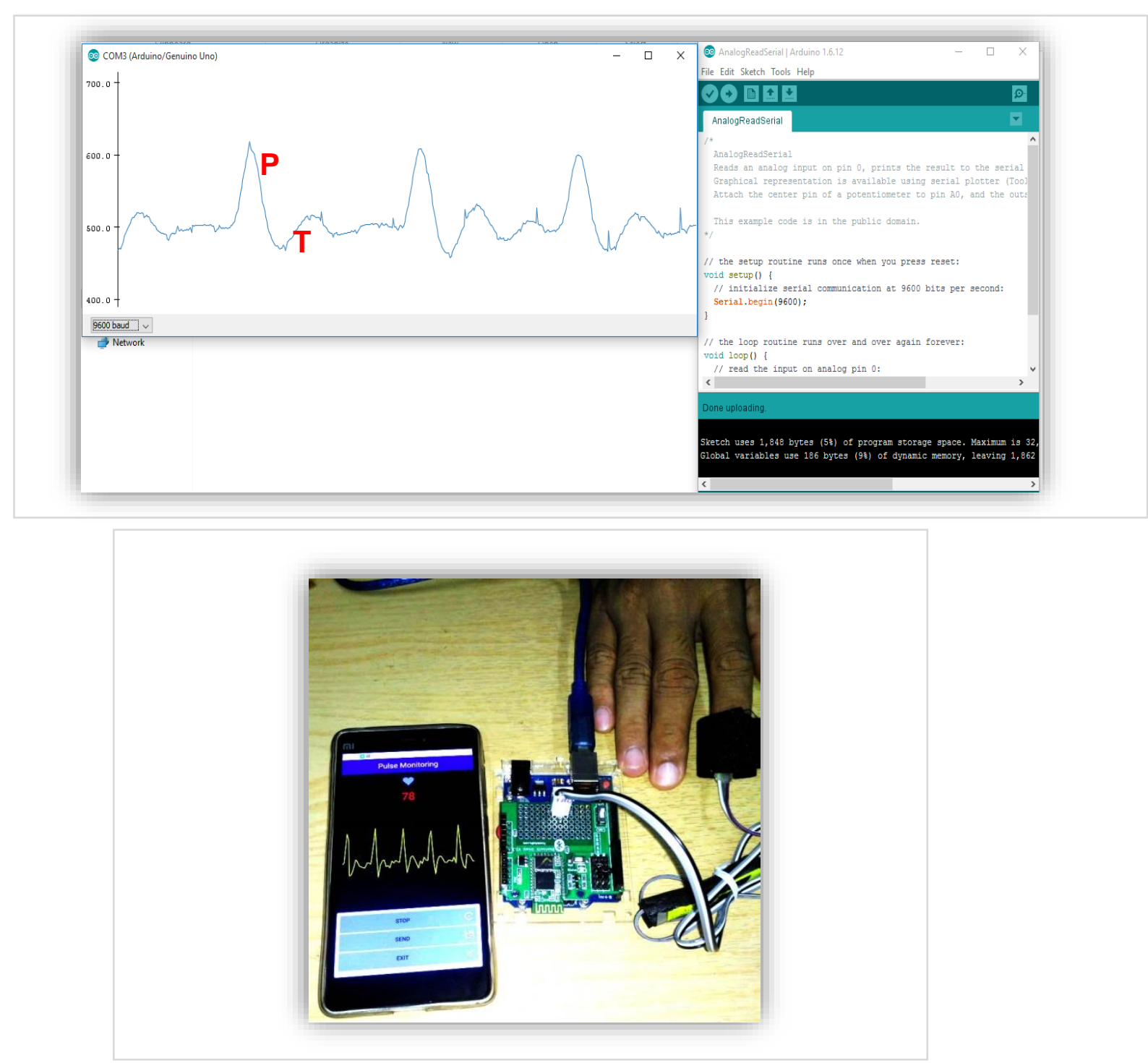

\section{Gambar 3. Perangkat Pulse Monitoring}

Selanjutnya dilakukan pengujian koneksi nirkabel antara perangkat arduino dan sensor, Grafik yang berjalan secara realtime pada perangkat smartphone menggunakan koneksi Bluetooth (Gambar 3), langkah selanjutnya dilakukan pengujian dengan mengirimkan data dari perangkat smartphone android menuju web server dimana data pasien tersimpan dan terekam dengan periode yang di inginkan serta dapat pula dipantau oleh tim medis berdasarkan waktu pemeriksaan. Untuk melihat proses pengukuran denyut 
jantung dapat dilihat pada Gambar $\mathbf{4}$ flowchart bagian tim medis grafik realtime data denyut jantung akan terkirim secara otomatis menampilkan data denyut jantung pasien.

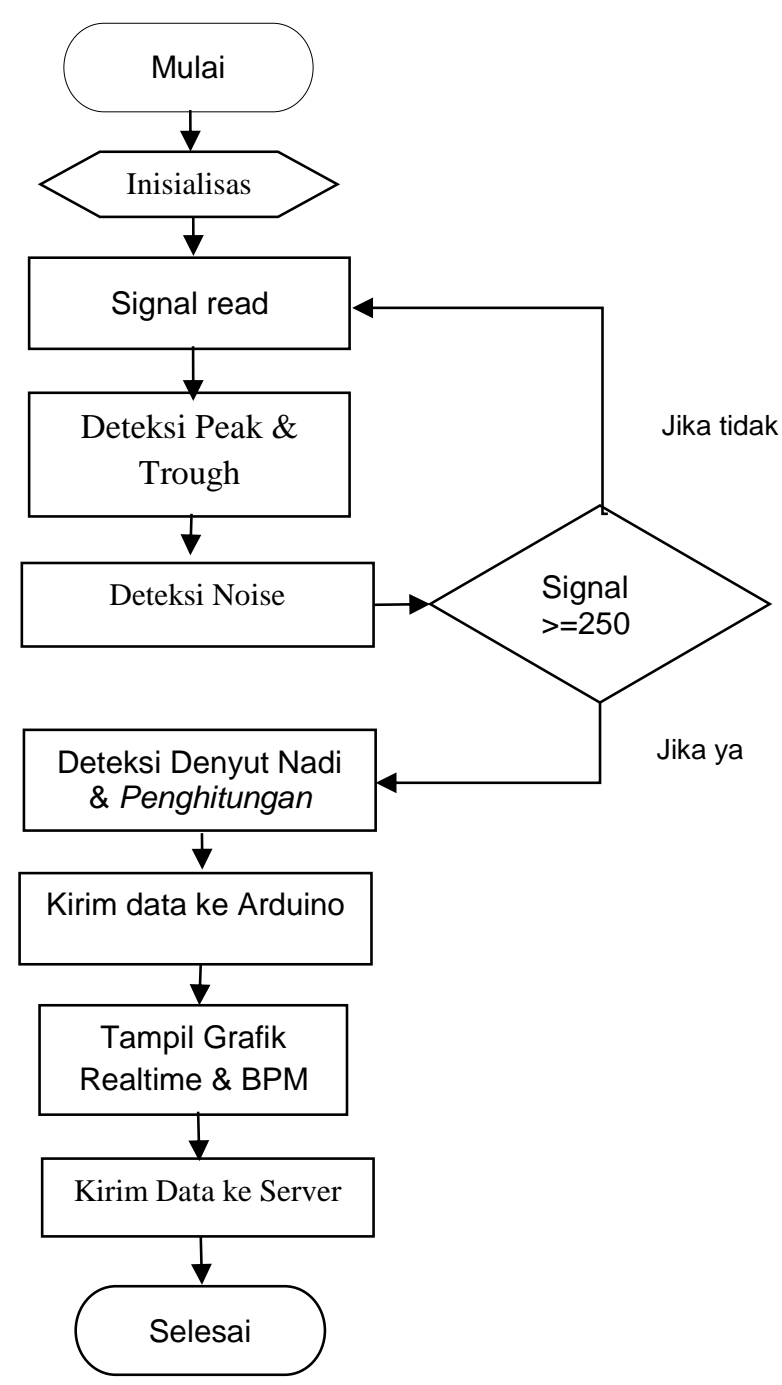

Gambar 4. FlowChart Deteksi BPM

\section{Pengujian Sistem}

Pengujian sistem dilakukan untuk melakukan pengujian terhadap seluruh bagian dari sistem terlihat pada Gambar 1, bagian (A) merupakan modul perangkat inputan yang terdiri dari sensor Pulse, Bluetooth Shield dan Arduino dimana modul input (A) akan mengirimkan sinyal analog perangkat android (B). dilanjutkan dengan memvisualisasikan nilai yang diperoleh dari modul (A). pengukuran BPM dilakukan dikirim melalui jaringan 
Internet $(\mathrm{C})$ dan data akan disimpan pada server yang terintegrasi dengan database dan web server. Selanjutnya Tim medis (E) dapat memantau dan secaara otomatis akan menerima data pasien secara realtime. Hasil pengiriman data ditentukan oleh jaringan internet yang terkoneksi dengan baik. Sehingga sewaktu-waktu pasien maupun tim medis ingin melihat data medical record bisa diakses kapan saja dan dimana saja yang di visualisasikan kedalam bentuk grafik yang dapat dilihat pada Gambar 1 bagian (F).

\section{Hasil Pengujian Terhadap Sampel}

Pengujian perangkat dilakukan terhadap sampel untuk menguji akurasi hasil pengukuran yang ada pada tampilan aplikasi. Prosedur yang dilakukan adalah dengan mangambil data pada sensor selama 30 detik, hasil tersebut dikirimkan menggunakan perangkat mobile yang telah terkoneksi internet dan dibandingkan dengan data uji manual menunjukkan hasil pengukuran yang stabil dengan sepuluh kali uji coba sehingga diperoleh rata-rata error sampel pertama sebesar $2.83 \%$ yang terdapat pada Tabel 1.

Tabel 1. Hasil Rata-Rata Pengukuran Seluruh Sampel

\begin{tabular}{|c|c|c|c|c|}
\hline No & Nama & $\begin{array}{c}\text { Pengukuran } \\
\text { Manual }\end{array}$ & Pulse Sensor & $\%$ Error \\
\hline 1 & Fahmi & 70.7 & 68.9 & $2.83 \%$ \\
\hline 2 & untung & 72.8 & 72.7 & $1.51 \%$ \\
\hline 3 & wahyu & 60.2 & 60 & $1.00 \%$ \\
\hline 4 & Arifin & 91.9 & 91 & $1.19 \%$ \\
\hline 5 & Basrum & 89.1 & 88.1 & $1.56 \%$ \\
\hline 6 & Ansar & 83.9 & 82.8 & $2.02 \%$ \\
\hline 7 & Awal & 89.9 & 88.2 & $1.88 \%$ \\
\hline 8 & Djorji & 91.3 & 90 & $1.42 \%$ \\
\hline 9 & Gunawan & 82.4 & 81.77 & $1.68 \%$ \\
\hline 10 & Syam & 71.3 & 70.4 & $1.25 \%$ \\
\hline \multicolumn{5}{|c|}{ Rata-Rata Error } \\
\hline
\end{tabular}

\section{PEMBAHASAN}

Penelitian ini menunjukkan bahwa pulse sensor dibaca oleh Arduino Uno secara periodik berdasarkan nilai serial yakni 38400 bit per second untuk memberikan pola gelombang denyut jantung yang semirip mungkin dengan aslinya. Waktu gelombang yang terlalu kecil akan menghasilkan plot grafik yang berbeda dapat mempengaruhi hasil pengukuran. 
Pengujian dilakukan untuk memastikan pulse sensor dalam kondisi baik dari segi data masukan pembacaan sinyal analog sensor yang diuji pada perangkat Arduino yang dihubungkan secara serial melalui port USB komputer dan output ditampilkan mengunakan aplikasi Arduino IDE dengan tool serial plotter. Gelombang photoplethysmogram yang dihasilkan kemudian dibandingkan dengan hasil yang diperoleh pada perangkat mobile untuk melihat keseuaian pola antara perangkat mobile dan hasil serial plotter pada komputer. Data masukan yang dikirim pada perangkat mobile dilakukan proses filterisasi sehingga noise yang terdapat pada serial plotter dapat dihilangkan.

Proses yang terjadi setelah pembacaan pulse sensor adalah transmisi data. Selama proses ini, arduino menyimpan hasil perhitungan dari perangkat pulse sensor. Dan kembali mengupdate data sesuai data inputan yang masuk pada sensor pulse. Arduino mengambil data yang tersimpan dalam array dihitung menghasilkan sebuah variabel BPM yang secara terus menerus dikirimkan dari perangkat arduino menuju perangkat mobile menggunakan koneksi bluetooth. Perangkat android melakukan komunikasi dengan web server untuk menyimpan variable BPM yang dikirimkan perangkat smartphone android kedalam MySQL server untuk menyimpan informasi BPM dari user yang melakukan pengiriman data.

Hasil pengujian transmisi data menunjukkan bahwa proses transmisi nilai variable BPM ke informasi ke MySQL server telah berhasil dengan baik. Dibuktikan dengan hasil perhitungan yang tampil menggunakan perangkat mobile, Transmisi pertama yang dikerjakan adalah perangkat mobile menuju web server. Dimana jika proses ini gagal, informasi notifikasi pada perangkat smartphone android akan tampil yang menandakan data yang dikirim ke MySQL server gagal untuk disimpan, sebaliknya jika proses ini berhasil android device akan melakukan transmisi dimana setiap variabel yang menjadi inputan pada server dikirim dan tersimpan MySQL server sehingga muncul pula pesan yang menandakan bahwa data yang direkam telah tersimpan pada Mysql Server.

Faktor utama yang mempengaruhi proses transmisi adalah kualitas layanan internet dari ISP (Internet Service Provider) yang ada pada perangkat smartphone android, selain itu harus dipastikan bahwa perangkat android memiliki paket data dan perangkat mobile tersebut tidak memiliki pengaturan firewall yang mengeblok komunikasi menuju ke server.

Hasil pengolahan data grafik photoplethysmogram menghasilkan tegangan yang dikeluarkan oleh pulse sensor nilai tersebut sebagai signal beat dimana threshold untuk 
menentukan titik puncak tertinggi sudah ditentukan kedalam source code begitupun dengan titik rendah atau dikatakan sebagai titik Trough (palung) ketika keduanya sudah dideteksi selanjutnya akan menghitung total sample rate yang telah diterima dari sensor disimpan kedalam array serta di kalkulasi dibagikan dengan satuan waktu selama 60000 milisecond atau setara dengan satu menit. Denyut jantung manusia normal untuk laki-laki adalah 70 BPM dan 75 BPM untuk wanita dewasa (Suryawanshi \& kurhade, 2013). Untuk mengukur nilai error dilakukan perbandingan nilai pulse yang dihitung secara manual selama 60 detik dan dibandingkan dengan hasil yang didapatkan dengan perangkat yang telah dirancang pada saat yang sama, dapat dilihat bahwa hasil pengukuran detak jantung pada pengukuran sampel pertama. Menunjukaan nilai kesalahan yang relatif kecil dimana hasil rata-rata dari sepuluh sampel dimana satu sampel di ujicoba sebanyak sepuluh kali uji coba menghasilkan tingkat error rata-rata sebesar $1.63 \%$. Hasil yang lain dapat dilihat adalah pola grafik yang tersimpan berdasarkan satuan waktu pengukuran. Selanjutnya, grafik yang dihasilkan ini dapat dianalisis lebih lanjut oleh dokter.

\section{KESIMPULAN DAN SARAN}

Berdasarkan dari penelitian yang telah dilakukan dengan mengusulkan sebuah prototipe sistem monitoring denyut jantung yang terintegrasi dengan perangkat keras sensor yang terintegrasi menghasilkan akurasi data yang sangat baik dimana data sebanyak 100 kali uji didapatkan error sebesar $1.63 \%$ yang dapat dilihat pada Tabel 1. Noise yang terdapat pada sinyal yang dihasilkan perangkat sensor telah difilter sebelum sampai pada perangkat smartphone android sehingga hasil pembacaan memiliki nilai error yang relatif lebih kecil. Selain itu sistem yang ada pada tim medis maupun admin dapat monitoring data denyut jantung pasien secara realtime, pasien juga dapat melihat medical record kapan saja dan dimana saja dengan menggunakan perangkat mobile mereka, saran pengembangan aplikasi kedepannya adalah dapat dikembangkan agar menghasilkan tingkat error yang relatif lebih kecil serta pengembangan aplikasi ini dapat berjalan pada platform selain android misalnya iPhone dan menambah parameter kesehatan seperti tekanan darah, suhu tubuh, pernafasan.

\section{DAFTAR PUSTAKA}


Americaan Heart Assosiation. (2016). My Heart and Stroke News. Diakses 19 November 2016. Available from: http://www.heart.org/HEARTORG/

Asfuah S. (2012). Buku saku Klinik Untuk Keperawatan dan Kebidanan. Yogyakarta: Nuha Medika.

Arduino. (2018). Arduino Getting Start and Learning. Diakses 1 September 2018. Available from: http://www.arduino.cc

Liu E F., Chen L., \& Gao B X. (2012). Sinus bradycardia: normal phenomenon or risk factor? Evaluation based on recent evidence. Journal of Insurance Medicine (New York, N.Y.), 43(2): 102-11.

Nuary F. (2010). Photoplethysmograph Berbasis PC Dengan Soundcard. Bandung: Institut Teknologi Telkom

Pressman R.S. (2009). Rekayasa Perangkat Lunak. Yogyakarta:Andi Publisher.

Pulse Sensor. (2018). Getting Start Pulse Sensor. Diakses 2 September 2018. Available from: http://pulsesensor.com/pages/processing-visualization

Rusmin \& Iqra. (2012). Implementasi dan evaluasi kinerja aplikasi jaringan sensor nirkable untuk monitoring kondisi denyut nadi pasien, Jurnal Universitas Hasanuddin

Santi., Palantei E., \& Ilham A.A. (2014). Pengembangan tampilan visual data medis Pada jaringan telemedis interaktif. Jurnal Universitas Hasanuddin

Sonal S., Tayade., \& Patil S.B. (2014). Medical Application of RISC core on single FPGA, International Journal of Engineering Trends and Technology (IJETT) 10(6):267- 270

Suryawanshi C. \& Kurhade B. (2013). Healthcare Monitoring System Based On Pulse Sensor. ljsr.Net, 4(4): 2946-2949 